\title{
A dose audit of fluoroscopy examinations at Charlotte Maxeke Johannesburg Academic Hospital: Analysis of preliminary results
}

\section{T Nyathi, MSc}

School of Physics, University of the Witwatersrand, Johannesburg

\author{
M L Pule, BSc (Hons) Med Sci \\ P Segone, BSc (Hons) Med Sci \\ D G van der Merwe, PhD
}

Division of Medical Physics, Charlotte Maxeke Johannesburg Academic Hospital

S P Rapoho, NDip (DR)

Division of Radiology, Charlotte Maxeke Johannesburg Academic Hospital

\begin{abstract}
Purpose. To retrospectively analyse the radiation doses delivered to patients undergoing fluoroscopy examinations in terms of the skin dose and the dose-area product (DAP) readings.

Materials and methods. The subjects of this study were patients who underwent fluoroscopy examinations on either of the two available digital Philips Medical Systems MultiDiagnost Eleva fluoroscopy units at Charlotte Maxeke Johannesburg Academic Hospital during the period August 2007 to March 2008. The skin dose was computed by the system's computer while the DAP values were obtained from a built-in DAP meter installed on the fluoroscopy unit. The following tests were performed: barium swallow, barium meal, barium enema, hexabrix swallow, gastrografin meal, voiding cystourethrogram, fistulogram, myelogram, nephrostomy and loopogram.

Results. An analysis of 331 examinations is presented. The following values were deduced from the recorded data: the mean and range of the skin doses and DAPs, mean screening time and mean fluoroscopy duration. An analysis of the screening time for the various examinations showed a weak correlation $(r=0.59)$ between skin dose and screening time, while a poor correlation $(r=0.42)$ was deduced between DAP reading and screening time.

Conclusion. There was a wide spread in the radiation doses registered for any one given type of examination. The large variability in the radiation dose delivered shows that fluoroscopic examinations stand to gain from dose optimisation. The usefulness and potential use of DAP meters for dose optimisation in radiology are shown. In line with efforts to optimise the dose from diagnostic radiography examinations, the authors recommend the establishment of diagnostic reference levels (DRLs) in South Africa for the most frequent examinations in general radiography, fluoroscopy, mammography and computed tomography.
\end{abstract}

\section{Introduction}

Diagnostic X-raying is ubiquitous in modern medical care. ${ }^{1}$ Medical ionising radiation is by far the largest man-made source of such radiation to impinge on the population, and most of this comes from diagnostic X-rays. ${ }^{2-4}$ South Africa is a health care level II country, according to the United Nations Scientific Committee on the Effects of Atomic Radiation (UNSCEAR) definition based on physician densities. ${ }^{5}$ This health care level classification translates broadly to $150 \mathrm{X}$-ray examinations per 1000 inhabitants. ${ }^{6}$ Given this relatively high frequency of X-ray examinations, it would be a disservice for the scientific community not to investigate population doses with the aim of optimising delivery of this medical service.

Ionising radiation is known to cause malignancies, skin damage and other side-effects and is therefore potentially dangerous. ${ }^{7-9}$ Consequently, there is ongoing concern about the use of ionising radiation in diagnostic radiology. In comparison with radiotherapy, this concern arises because many of the patients generally have a higher degree of child-bearing and life expectancy than those undergoing radiotherapy. This means that the genetic risk is higher and, in the case of younger patients, there is a greater risk of radiation-induced malignancies.

Irradiation for medical purposes differs from most other types of radiation exposure in that the benefit is normally limited to the person receiving the dose, and it is assumed that the benefit outweighs any associated hazard. Nevertheless, it is necessary to ensure that all doses are kept as low as is compatible with good medical practice. ${ }^{2}$

In line with the 'as low as reasonably achievable' (ALARA) principle, the Directorate of Radiation Control (DRC) in the national Department of Health has mandated all facilities having fixed fluoroscopy X-ray units to have a dose-area product (DAP) meter installed in their units and, from 1 January 2008, also to record the DAP readings after an examination. ${ }^{10}$ This legal requirement was communicated as an annexure to the licensing document for all fixed fluoroscopy units. In response to this directive, the Division of Radiology at Charlotte Maxeke Johannesburg Academic Hospital (CMH) started recording DAP meter readings and skin dose from 14 August 2007.

The DRC directive was premised on the fact that fluoroscopy examinations are generally high-dose examinations. Ionising radiation has either stochastic or deterministic effects on the exposed individual. In comparison with stochastic effects, deterministic effects are a lesser cause of concern in diagnostic radiology as they occur above a certain threshold dose, which is relatively high and can be avoided by having astute radiologists who monitor changes in the patient's skin during the examination and change the X-ray beam projections. It is the stochastic effects that occur at any dose level that are of concern, as they are potentially carcinogenic and can cause gene mutations in subsequent generations. 
The following measures can be implemented to reduce radiation doses to patients undergoing fluoroscopic examinations: ${ }^{11}$

- use of a heavily filtrated X-ray beam

- restriction of the X-ray field size to the region of interest

- keeping the X-ray tube at the maximal distance from the patient while the image intensifier is kept as close as possible to the patient

- keeping beam ON time to an absolute minimum

- using pulsed mode fluoroscopy

- maintaining awareness of the 5-minute time notifications

- using Last-Image-Hold facilities

- keeping tube current as low as possible

- keeping $\mathrm{kVp}$ as high as possible, bearing in mind patient thickness

- not using the anti-scatter grid

- using high-speed screen-film combinations

- maintaining room lighting to a minimum to optimise image viewing.

It is apparent from the above measures that dose optimisation is an inexpensive process. In addition, most measures that lead to patient dose reduction also yield a reduction in occupational dose, therefore radiation workers themselves stand to benefit.

\section{Aim}

The objectives of this study are to:

- deduce the level of compliance with the license conditions

- collect dosimetric data to alert medical physicists, radiologists and radiographers to the radiation doses delivered during fluoroscopic examinations with a view to further optimise the radiological technique

- report on the usefulness of DAP meters in the dose optimisation process.

\section{Materials and methods}

In compliance with the license conditions, patient details and DAP meter readings are recorded for every patient presenting for fluoroscopy examination at the CMH Division of Radiology. Patient and fluoroscopy data were therefore collected retrospectively from the record book. The

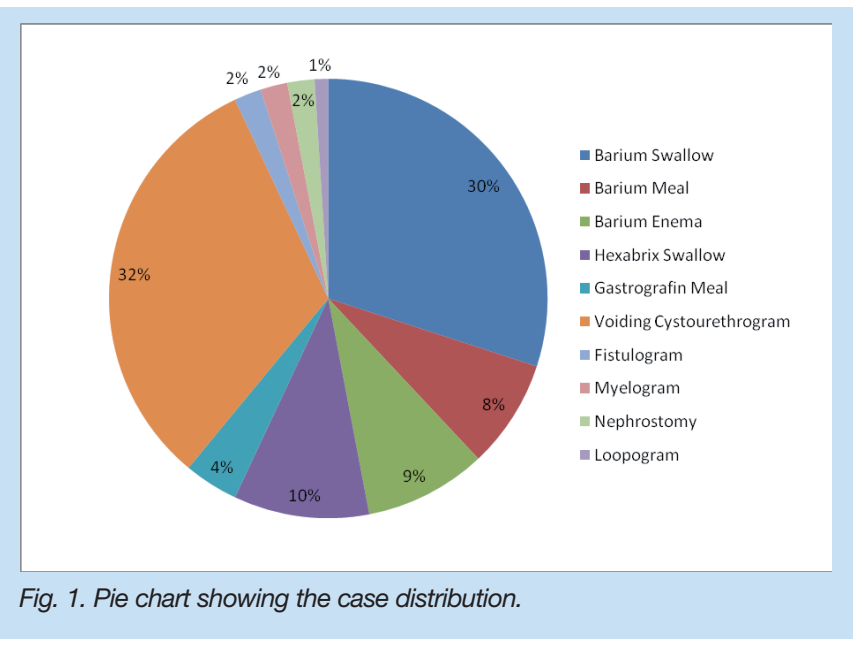

following patient parameters were recorded: full names, gender, age, type of examination, contrast agent used, clinician(s) performing the examination, radiographer(s) performing the screening, screening time and duration of the procedure. A total of 331 patients ranging in age from 16 to 88 years (mean age 51.2 years) underwent a variety of fluoroscopic examinations between 14 August 2007 and 26 March 2008. The patient population comprised 159 males and 172 females. The following tests were performed: barium swallow, barium meal, barium enema, hexabrix swallow, gastrografin meal, voiding cystourethrogram, fistulogram, myelogram, nephrostomy and loopogram.

All examinations were performed on a digital Philips Medical Systems MultiDiagnost Eleva fluoroscopy unit; this has a built-in DAP meter installed at the X-ray tube exit. The DAP reading is given in $\mu \mathrm{Gym}^{2}$. In addition, the X-ray unit's computer system computes the skin dose in $\mathrm{mGy}$. The unit is periodically serviced and appropriate quality assurance tests performed.

This review study involved 48 clinicians and 37 radiographers of varying experience in their practices. The adopted technique for any particular examination was at the discretion of the radiologists.

\section{Results}

A total of 331 patient examinations were recorded and analysed; the distribution of these examinations were stratified according to type of case, as shown in Fig. 1. The majority of the examinations were for the upper gastrointestinal tract. The ranges and means for each type of examination were calculated from the individual patient records of the skin dose and DAP reading. The results are shown in Table I. An analysis of the range of both the skin doses and DAPs shows a wide variation within one examination.

Time, in terms of the screening time and duration of the whole procedure, has a big impact on the patient dose. As such, the mean screening time and mean procedure duration per examination were calculated, as shown in Table II. Statistical analysis showed that the coefficient of correlation between the screening time and skin dose for all the studied examinations was equal to 0.59 . Furthermore, the coefficient of correlation between screening time and the DAP readings was 0.42 for the same examinations.

\section{Discussion}

It was noticed that some patients did not have their DAP reading or skin dose recorded after an examination. However, it is encouraging that the recording process has significantly improved. The documentation process was still in its initial phase for the period under review, so it is assumed that some radiographers were not yet accustomed to recording the data and would tend to forget. The division's decision to start recording DAP readings on 14 August 2007 paid dividends as, by 1 January 2008 , the process was fully compliant with the DRC's requirements. In addition, it is good practice to document all patient examination-related parameters for the purposes of comparison with other radiology departments and also as a quality control measure with the aim of continually improving the process.

An analysis of the screening time for the various examinations showed a weak correlation $(r=0.59)$ between skin dose and screening time, while a poor correlation $(r=0.42)$ was found between DAP read- 


\section{REVIEW ARTICLE}

Table I. Mean skin dose and DAP for various examinations (range of measured skin dose and DAP readings in parentheses)

\begin{tabular}{|c|c|c|c|}
\hline Examination & Number of examinations & $\begin{array}{l}\text { Mean skin dose } \\
\text { (mGy) }\end{array}$ & $\begin{array}{l}\text { Mean DAP } \\
\left(\mu \mathrm{Gym}^{2}\right)\end{array}$ \\
\hline Barium swallow & 101 & $\begin{array}{l}79 \\
(62-347)\end{array}$ & $\begin{array}{l}1912 \\
(235-7276)\end{array}$ \\
\hline Barium meal & 27 & $\begin{array}{l}127 \\
(38-395)\end{array}$ & $\begin{array}{l}2343 \\
(47-6505)\end{array}$ \\
\hline Hexabrix swallow & 35 & $\begin{array}{l}57 \\
(7-242)\end{array}$ & $\begin{array}{l}1643 \\
(241-9712)\end{array}$ \\
\hline Gastrografin meal & 12 & $\begin{array}{l}75 \\
(10-131)\end{array}$ & $\begin{array}{l}2689 \\
(167-6979)\end{array}$ \\
\hline Barium enema & 31 & $\begin{array}{l}177 \\
(55-487)\end{array}$ & $\begin{array}{l}5062 \\
(519-20296)\end{array}$ \\
\hline Voiding cystourethrogram & 106 & $\begin{array}{l}63 \\
(7-579)\end{array}$ & $\begin{array}{l}1560 \\
(130-1626)\end{array}$ \\
\hline Fistulogram & 7 & $\begin{array}{l}71 \\
(9-155)\end{array}$ & $\begin{array}{l}1320 \\
(154-2559)\end{array}$ \\
\hline Myelogram & 6 & $\begin{array}{l}117 \\
(1-292)\end{array}$ & $\begin{array}{l}1821 \\
(14-5266)\end{array}$ \\
\hline Nephrostomy & 8 & $\begin{array}{l}38 \\
(7-179)\end{array}$ & $\begin{array}{l}1458 \\
(161-2559)\end{array}$ \\
\hline Loopogram & 3 & $\begin{array}{l}31 \\
(22-49)\end{array}$ & $\begin{array}{l}810 \\
(746-910)\end{array}$ \\
\hline
\end{tabular}

Table II. Mean screening time and mean procedure duration per examination type ${ }^{\star}$

\begin{tabular}{lll}
\hline Examination & $\begin{array}{l}\text { Mean } \\
\text { screening } \\
\text { time } \\
\text { (minutes) }\end{array}$ & $\begin{array}{l}\text { Mean } \\
\text { fluoroscopy } \\
\text { duration } \\
\text { (minutes) }\end{array}$ \\
Barium swallow & 4 & 27 \\
Barium meal & 7 & 43 \\
Hexabrix swallow & 3 & 24 \\
Gastrografin meal & 4 & 47 \\
Barium enema & 10 & 54 \\
Voiding cystourethrogram & 4 & 41 \\
Fistulogram & 3 & 34 \\
Myelogram & 54 & 55 \\
Nephrostomy & 8 & 93 \\
Loopogram & 2 & 22 \\
& & \\
& Values of screening time and fluoroscopy duration to the nearest integer.
\end{tabular}

ings and screening time. In addition, the poor correlation could be attributed to the fact that fluoroscopic examinations are complex and varied. The poor correlation should be interpreted cautiously as the fluoroscopy screening time is of limited use, because it makes no allowance for the influence of dose rate or field size.

Despite the use of a single dedicated fluoroscopy suite, there was a wide variation in measured skin doses and DAPs within any type of examination. $\mathrm{CMH}$ is a training institution, and this variation could be a result of variation in experience of both radiographer and radiologist. Moreover, relatively high doses were recorded, which could arise from the fact that the current survey is for a university hospital where the proportion of complicated cases could be relatively high and where there are many radiology registrars undergoing their training. However, despite present barium meal DAP readings not being corrected for patient mass, the mean DAP value $\left(23 \mathrm{Gycm}^{2}\right)$ is comparable with a mean DAP value of $23.2 \mathrm{Gycm}^{2}$ from an international study conducted by the International Atomic Energy Agency (IAEA). ${ }^{12}$ This means that our practice is on a par with other international centres, although there is room for improvement.

Fluoroscopy examinations can lead to various radiation effects, i.e. transient erythema, epilation, erythema, pericarditis, dermal necrosis, symptomatic skin reactions, non-symptomatic skin reactions and skin cancer, depending on the duration of the beam ON time. To prevent skin injuries, the entrance surface doses should be monitored from direct dose measurements or from observing the change in the patient's skin colour. Should the procedure be prolonged unexpectedly, the radiologist should consider changing the position of the patient, altering the X-ray field size or altering the X-ray beam angulation so that the same skin area is not continuously in the direct X-ray field.

The International Commission on Radiological Protection (ICRP) has recommended the use of diagnostic reference levels (DRLs) as a first step in the optimisation of diagnostic radiography. DRLs are defined as dose levels in medical radio-diagnostic practices or, in the case of radiopharmaceuticals, levels of activity, for typical examinations for groups of standard-sized patients or standard phantoms for broadly defined types of equipment. ${ }^{9}$ A DRL is not a dose limit and it does not apply to a single 
individual; it must be established for typical examinations, for groups of standard-sized patients or standard phantoms, and for broadly defined types of equipment. These levels are expected not to be exceeded for standard procedures when good and normal practice regarding diagnostic and technical performance is applied.

\section{Conclusion}

Data from 331 fluoroscopy examinations were collected and analysed. There was a wide spread in the radiation doses registered for any one type of examination, possibly as a result of a variation in the degree of complexity of the examination, variability in the X-ray exposure settings, non-homogeneity in patient sizes, differing radiologists' preferences and the experience of the radiographer. The large variability in delivered radiation dose proves that the studied fluoroscopic examinations stand to gain from dose optimisation. In addition, this study shows the potential usefulness of DAP meters in radiology for dose optimisation. In line with efforts to optimise diagnostic radiography, the authors recommend the establishment of DRLs in South Africa for the most frequent examinations in general radiography, fluoroscopy, mammography and computed tomography. We further suggest that a common protocol be used nationwide in determining patient doses for the purposes of establishing DRLs - for example, the IAEA Technical Report Series Number 457, Dosimetry in Diagnostic Radiology: An International Code of Practice. ${ }^{2}$
We thank all the radiographers who worked at the fluoroscopy unit during the period under review, and the Human Research Ethics Committee at the University of the Witwatersrand for approving this research.

1. Wagner LK, Lester RG, Saldana LR. Exposure of the Pregnant Patient to Diagnostic Radiations: A Guide to Medical Management. 2nd ed. Wisconsin: Medical Physics Publishing Madison, 1997: 3.

2. International Atomic Energy Agency. Dosimetry in Diagnostic Radiology: An International Code of Practice. Vienna: IAEA, 2006.

3. Kendall GM, Darby SC, Harries SV, Rae S. A frequency survey of radiological examination carried out in national health service hospitals in Great Britain in 1977 for diagnostic purposes. Report R104. London: National. Radiological Protection Board, 1980.

4. Ogundare FO, Uche CZ, Balogun FA. Radiological parameters and radiation doses of patients undergoing abdomen, pelvis and lumbar spine x-ray examinations in three Nigerian hospitals. Br J Radiol 2004; 77: 934-940.

5. World Health Organization. Country data. http://www.who.int/whosis/database/core/core_select_process. cfm (accessed 24 October 2008)

6. UNSCEAR. Report to General Assembly. http://www.unscear.org/docs/reports/gareport.pdf. (accessed 24 October 2008).

7. Hall E J. Radiobiology for the Radiologist. 3rd ed. Philadelphia: JB Lippincott, 2000: 385-409.

8. Travis EL. Primer of Medical Radiobiology. 1st ed. Chicago: Year Book Medical Publishers, 1975: 135-149.

9. Council Directive $97 / 43$ Euratom of 30 June 1997 on health protection of individuals against the dangers of ionizing radiation in relation to medical exposure, and repealing Directive 84/466/Euratom. Official Journal of the European Commission 9 July 1997; No. L 180/22-27.

10. Directorate: Radiation Control. Radiography conditions (excluding radiotherapy simulators). Annexure to Licence. Pretoria: Department of Health http://www.doh.gov.za/department/radiation/01.html (accessed 24 October 2008).

11. Bushberg JT, Seibert JA, Leidholdt EMJR, Boone JM. The Essential Physics of Medical Imaging. 2nd ed. Philadelphia: Lippincott Williams \& Wilkins, 2002: 251-252.

12. International Atomic Energy Agency. Optimization of the radiological protection of patients undergoing radiography, fluoroscopy and computed tomography. IAEA-TECDOC-1423: Final report of a coordinated research project in Africa, Asia and Eastern Europe. Vienna: IAEA, 2004.

\section{Why and wherefore the RSSA? (continued from page 22)}

4. Public relations

4.1 Mammography month October 2008

4.2 CCTA and virtual colonoscopy media promotion, April to June 2009

5. Health policy

5.1 Participation in various private sector task teams

The RSSA endeavours to continue serving its members, and invites comment and advice on policy direction and the work done. The RSSA cannot perform its functions without a full complement of paid-up members. If you are benefiting from the work of the RSSA and are not currently a member, please consider joining your colleagues.

\section{Clive Sperryn}

RSSA President 